\title{
Philosophiques
}

\section{Catherine Larrère, L'invention de l'économie au XVIII siècle, Paris, P.U.F., 1992, 326 pages.}

\section{Marie Guertin}

Volume 21, numéro 1, printemps 1994

URI : https://id.erudit.org/iderudit/027264ar

DOI : https://doi.org/10.7202/027264ar

Aller au sommaire du numéro

Éditeur(s)

Société de philosophie du Québec

ISSN

0316-2923 (imprimé)

1492-1391 (numérique)

Découvrir la revue

Citer ce compte rendu

Guertin, M. (1994). Compte rendu de [Catherine Larrère, L'invention de

l'économie au XVIII siècle, Paris, P.U.F., 1992, 326 pages.] Philosophiques, 21(1),

268-270. https://doi.org/10.7202/027264ar d'utilisation que vous pouvez consulter en ligne.

https://apropos.erudit.org/fr/usagers/politique-dutilisation/ 
Catherine Larrère, L'invention de l'économie au XVIII ${ }^{e}$ siècle, Paris, P.U.F., 1992, 326 pages.

\section{par Marie Guertin}

Le but de $C$. Larrère est de faire un historique de l'invention de l'économie au XVIII ${ }^{e}$ siècle en France, historique qui s'attache pour l'essentiel aux physiocrates, dont on se propose ici de renouveler l'étude. Car depuis igro, ces derniers n'auraient fait l'objet d'aucun veritable travail scientifique : alors qu'on croit bien les connaître, en vérité on les connaît peu ou mal. Bref les physiocrates français sont passés dans l'oubli au profit d'Adam Smith.

I'auteur, dans les deux premiers chapitres intitulés « Droit naturel et sociabilité » (p. 17-57) et « La sociabilité des Lumières » (p. 59-93), rattache l'école 
physiocratique à la tradition européenne et à la philosophie des Lumières. Car, d'une part, la pensée des juristes, tels que Barbeyrac, Burlamaqui, Grotius et Pufendorf, a profondément marqué la théorie économique française, mais, d'autre part, celle-ci a été influencée par les Encyclopédistes, ainsi d'Alembert, Condillac, Diderot et même Rousseau.

Ceci fait, C. Larrère passe à l'analyse directe des économistes français du XVIII siècle, qu'elle rattache aussi cependant aux économistes anglais Law et Child. Elle s'attarde non seulement sur les auteurs les plus connus du public cultivé, tels que Gournay, Morellet, Quesnay et Turgot, mais encore elle fait connaitre avec précision des auteurs moins connus, mais qu'elle révèle fort intéressants, comme d'Argenson, Baudeau, Coyer, Cliquot-Blervache, Forbonnais, Galiani, Herbert, Melon, Mercier de la Rivière, Moreau et Plumart de Dangeul.

Le chapitre III, « Le mercantilisme : la rationalité du système » (p. 85-134), nous présente une vision comparée du mercantilisme anglais et du mercantilisme français, le premier tirant son inspiration de Machiavel, le second d'Aristote. Cette présentation, l'auteur la développe en exhumant et en analysant les écrits de deux représentants du mercantilisme français, qui eux-mêmes comparent les deux traditions, à savoir Forbonnais et Melon. Car ceux-ci ne sont nullement des fanatiques à tout crin du mercantilisme, quel qu'il soit, mais plutôt des mercantilistes « éclairés », puisqu'ils veulent faire du commerce une « science » et qu'ils travaillent dans l'entourage de Gournay. Leur pensée est d'ailleurs complexe : ouverts au commerce extérieur, ils tiennent cependant à la réglementation étatique du commerce intérieur et à quelque protectionnisme.

Le chapitre IV, « Les doux principes du commerce » (135-172), nous fait passer du mercantilisme français à la pensée économique de Gournay, qui incline davantage vers le mercantilisme britannique et s'attache à faire connaître en France les œuvres de Law et de Child. Toutefois Gournay n'adhère pas complètement à leur doctrine, car, même s'il n'aime pas le protectionnisme étatique dur, qui suscite méfiance et hostilité entre les partenaires commerciaux, il tente une sorte de synthèse entre liberté et protection, en particulier pour le commerce extérieur. C'est pourquoi du reste il invite le gouvernement français à se doter d'une marine marchande « à l'anglaise ». En un mot, il préconise une attitude de confiance, donc de sociabilité, dans les relations commerciales et encourage ce qu'il appelle « le doux commerce » dans la liberté, la concurrence légale et l'honnêteté. Ainsi il établit un pont entre le mercantilisme et ce que sera, ultérieurement, la physiocratie. Toute cette théorie de Gournay devait prendre forme lors du problème de l'importation des toiles peintes en France, importation que le gouvernement cherchait alors à arrêter.

Les chapitres V et VI, respectivement intitulés « L'invention de l'économie » (173-220) et « La philosophie des blés » (221-268), nous font entrer dans le développement de la physiocratie, par le biais de vifs débats, à propos de la question des grains et du blé en France, entre trois groupes principaux : mercantilistes, disciples du doux commerce et physiocrates. Ceux-ci pensent, on le sait, que l'agriculture a été délaissée au profit du développement des manufactures. Mais la question centrale est de savoir si la production agricole doit être conservée sur place comme réserve de subsistance ou si elle peut faire 
aussi l'objet d'un commerce extérieur. Les physiocrates, en particulier Coyer, qui invite les capitaux à s'investir dans les campagnes, et Quesnay, partisans de l'exportation même des grains, tiennent pour le second parti. Ce que Quesnay développe en distinguant subsistance et opulence, puis en recommandant la seconde, qui seule permettrait d'éviter la misẻre, à laquelle a condamné jusqu'ici la politique de subsistance. En d'autres termes, il prône pour l'agriculture une « politique de jouissance », que devait reprendre Turgot avec sa théorie des marchés. Mais, comme le montre le chapitre VII, la théorie des physiocrates, qui avait reçu un commencement d'application avec les édits de $1763-1764$, allait se trouver mise à mal par l'accentuation de la crise économico-politique qui frappait la France des années i 768-i770. Face au peuple qui s'effrayait de la fuite des blés, le gouvernement revenait à la politique du stockage. Ce qui n'empêcherait pas toutefois les physiocrates et leurs disciples, comme le montre aussi avec détail la suite du chapitre VI, de continuer à développer leurs réflexions dans la même direction en dépit d'adversaires illustres comme Galiani et Diderot.

Le dernier chapitre, intitulé « Sièyes : le gouvernement représentatif d'une république industrieuse » (269-307), analyse la lecture très originale que, dès I755 et jusqu'en 1775 , Sièyes a faite des physiocrates, notamment dans ses Lettres aux Economistes sur leur système de politique et de morale, ses Ecrits politiques, son Exposition raisonnée des droits de lHomme et du Citoyen, et même dans son célèbre Qu'est-ce que le Tiers Etat? L'originalité de Sièyes est de reprendre certaines idées physiocratiques sur une législation de l'économie conforme à l'ordre naturel pour les transformer en un vaste système politique et social. En d'autres termes Sièyes, grâce à sa théorie de la division du travail et de la représentation, réussit à jeter un pont entre la physiocratie et la politique, ce que les physiocrates eux-mêmes avaient cherché à faire, mais sans y parvenir.

En conclusion, nous n'hésitons pas à dire que le livre de C. Larrère a au moins un double mérite, tout à fait considérable: d'une part, celui de nous donner une représentation claire d'un phénomène historiqựe particulièrement complexe, à savoir, comme le dit le titre du livre, la genèse de la pensée économique française au XVIII siecle; d'autre part, de développer une analyse précise des thèmes débattus et des idées proposées. En outre, l'auteur a le talent de nous captiver tout au long de son étude, dont l'intérêt ne nous paraît guère moins actuel qu'historique, puisque le débat entre protectionnisme et le libéralisme nous agite toujours. Bref, fortement documenté, bien pensé et bien écrit, ce livre se recommande au lecteur cultivé aussi bien qu'au spécialiste.

\section{Département de philosophie}

Université d'Ottawa 